\title{
Discussion of Water Pollution Control Engineering teaching at expanding professional sustainability innovation capacity
}

\author{
Shuqin Zhang, Li Wang \\ College of Environment Science and Technology Wuhan University of Science and Technology, \\ Wuhan Hubei \\ zhangwuxia@163.com
}

Keywords: environmental engineering; teaching; innovation ability; professional.

\begin{abstract}
Environmental engineering education has been the focus of much attention in recent years. Teaching methods of water pollution control and sustainable teaching innovation and creation was explored by many scholars, and the majority of workers engaged in teaching the course. The development and future of environmental engineering professional teaching requirements of the course was describes in this paper. Diversity of environmental pollution control engineering curriculum innovation of the importance of education was elaborated. the establishment of a flexible operating platform engineering was proposed for the innovation education of the environmental engineering education; and the diversity and the innovation capability teaching platform and systems of creative ability of the education paradigm shift in a sustainable, effective and economical way were explored on the teaching of environmental engineering from the original model to a scientific, humanistic spirit.
\end{abstract}

Currently, the global environmental problems have become increasingly prominent, it was a seriously threat to the survival and development of human society. Environmental engineering education exists in almost all the universities in developed countries and is still being taught and delivered as part of the civil engineering programmes at many universities. Most programmes were developed in the 1960s and, at that time, environmental engineering education primarily was focused on the issue of sanitation.

However, today it has expanded to cover the air, land, water and human environment. Environmental engineering is growing and spreading rapidly across universities in developing countries [1]. National Environmental pollution control technology and control engineering technology development requires environmental pollution control technology innovation system needs more important technical support and personnel support. From a global perspective, that the energy and resource constraints, demographic changes, have prompted us to choose sustainable development [2].

With environmental engineering evolving into a discipline with its own identity and merits, it can be viewed as a positive move because it creates more job opportunities for the environmental engineering profession. Environmental engineering education in Chinese universities is also developing rapidly, in 1996 the country with environmental engineering undergraduate colleges and universities have more than 70, in September 1998 according to the new conducted by professional catalog statistics are 117 . In 2000, statistical results are that the country with environmental engineering undergraduate institutions amounted to 149. At present, China's environmental engineering undergraduate colleges and universities are widely distributed across almost every province, but correspondingly more concentrated in economically developed coastal areas, it is my school neighboring Jiangsu, Zhejiang and three provinces have 24 colleges and universities to set up the profession. In such an environment, how to highlight its own characteristics, to avoid blind repetition is particularly important.

Therefore, this paper will explore the teaching of environmental engineering courses should meet booming domestic environmental pollution and control engineering needs of the market, starting from the particularity of environmental engineering, to overcome some of the limitations of the teaching process, the use of the harmonious development of man and nature concept of the principle of sustainable innovation capability strengthen personnel education and thinking about the whole curriculum development of science, environmental engineering through flexible learning 
platform, highlighting the characteristics of colleges and universities and vocational needs of the market, to enhance the teaching culture of sustainable environmental engineering innovative teaching.

\section{Professional challenge for environmental engineering}

\subsection{Professional challenges for the development of environmental engineering}

Tansel believes that more environmental engineers with interdisciplinary training and global citizenship are required to meet this expanding market [3]. Such training can only be accomplished through appropriate environmental engineering education. Further, according to this, an interdisciplinary environmental education should cover a wide range of disciplines such as biology, ecology, public health, geology, and economics, and also include traditional subjects such as water, waste-water, air pollution and hazardous waste [4-6]. It is pleasing to observe that environmental engineering education has by now started to grow and spread across universities in the developing countries [7]. The rapid development of today's socio-economic, environmental engineering teaching situation is also currently facing challenges, not only how to coordinate the Higher Education and the environmental pollution control engineering specialization of social contradiction between demand and talent training mode and strengthening the current occupation the overall quality of the actual conflict between innovation and creativity.

\subsection{The challenge of social employment needs}

Since the state's emphasis on environmental governance, environmental engineering is currently setting up a few colleges and universities, but the graduate's employment situation is not optimistic. The situation seems to be that everyone is claiming to be an environmental engineer but no-one appears to really understand or truly know the meaning of this profession. In its attempt to propose a degree in environmental engineering to meet the growing demand of this profession, however, the related programme in environmental engineering is divided into two major groups, one majoring in environmental sciences and the other in traditional engineering. The approach adopted here is referred to as the add-on approach: that is, taking environmental engineering subjects and adding them on to existing programmes [6].

Along with pollution control thoughts and ideas change, environmental governance in the late 20th century from the end of the treatment completed the transition to pollution prevention. Environmental situation of the new changes, resulting in domestic environmental policy has undergone significant adjustment in higher education for the environment also had a greater impact. But the content covers a wide range, and no prior experience to draw on, need to continue to explore in the teaching practice and research.

\subsection{The challenge of teaching and social needs}

At present, China's environmental pollution has seriously affected the economy's sustainable development. How to develop suitable environment pollution control engineering talent needed for that environmental pollution control technology, systems integration, and demonstration and application process and mechanism innovation is the future of environmental pollution control technology development. Environmental engineers must face the future protection of the natural environment and avoid the destruction of the ecological environment; the process does not produce the material. In environmental governance process, not only to pay attention to the use of treated material, but also concerned about the use of the process resulting in residual substances, particularly health protection aspects of daily used drugs and their metabolites in handling. In environmental engineering vocational education and teaching, we should strengthen the sustainability of resources and the environment constitute the social, legal, political, natural sciences and engineering understanding of the many elements adoption of new testing and monitoring tools to expand the teaching, the development of new technologies and processes in teaching sustainability efforts reveal a complex system of many elements of mutual relations. 
Improving students' professional quality of the teaching process is the future key issues, through the quality of education and vocational education combine to enhance the adaptability of the students for the future, help students combine theory and practice of integrated development of multifaceted talent.

\section{Teaching and Innovative Education}

However, many courses and programmes are still being taught and delivered as part of civil engineering programmes. We strongly believe that environmental engineering education would be better delivered in a more specialized education programme rather than within the traditional education. Environmental engineering is different from any classical engineering discipline because it is multidisciplinary in nature, covering a broad range of topics from engineering and science, to economics and humanities, etc. Teaching environmental engineering, innovation and expansion of student ability is the core of teaching. Teaching, innovation comes mainly from the face to face learning by doing process, such as the MBR design and production, as well as the procedure. Through theory and practice of combining education, continually expanding environmental engineering teaching content, while teaching innovation is also environmental management industry and a source of wealth, the future of industry rely on what they have learned and innovative knowledge through rational use to more effective protection environment. This can help people to understand the existing environmental pollution control products, technologies or services, as well as the difference between the present and the past, grasp the future development, sustainable development of the power for the product to birth of a new creation, all of these are environmental engineering innovation.

Environmental engineering curriculum innovation education, core curriculum teaching methods change. Creative Ability innovative educational approaches and related infrastructure, the necessary resources into education is its material guarantee. In recent years, with the expansion of higher education and paid development of higher education institutions specialized educational resources into environmental engineering has been some improvement, but to satisfy the outstanding characteristics of professional and social needs, this investment also needs to be strengthened. Environmental Engineering in establishing innovative new teaching mode, the theory and engineering knowledge, innovation, new knowledge synthesis, a variety of theoretical knowledge dissemination, can make by students to have the ability to acquire new knowledge sustained in the future have the ability to innovation and creativity. In every aspect of teaching, the training received by students in the chaos of the facts can be integrated to solve future resource shortages.

\section{Flexible teaching platform and diversity of environmental engineering innovative teaching}

Environmental engineering education has grown, expanded and evolved into a unique area of engineering over the past decade, particularly across universities in Canada, Japan and USA. However, in many countries it still lacks identity as a discipline and as a profession within universities. This approach is one of taking an existing programme, for example, degree in environmental sciences, and adding to it subjects in environmental engineering.

The primary focus of environmental engineering education at universities in developing countries is on the basic infrastructure, sanitation, water supply, solid waste management, and low-cost, simple technology. The main teaching methodologies applied and proven effective include lectures, seminars, role-playing, video, Internet, study tours and field visits. There are also collaborative environmental engineering programmes established between universities from both developed and developing countries to promote the sharing of resources [8]. The authors strongly support the collaborative programmes, provided the local issues and problems are addressed appropriately in the curriculum. Such programmes may be a viable option for many universities where financial and human resources are scarce. Environmental pollution and control of flexible operating system that can help students perceive environmental pollution control engineering disciplines engineering philosophy and help students develop professional competence of future 
success. Teachers and students get in-depth understanding of the natural environment. For example, the complexity of the problem of water pollution, need to deal with engineering curriculum and teaching methods of the diversity and flexibility. By teaching diversity and flexibility training mode, to resolve practical needs of the market economy and vocational training mode unity of contradictions. Diversity and flexibility of curriculum can effectively improve the quality of education quality environmental engineering. Meanwhile, the engineering education should strengthen links with factories and enterprises, so that students can directly facing society pollution instance, to understand a typical case. These subjects include environmental impact assessment, environmental auditing, environmental ethics, environmental economics, ecological engineering and ecology [9].

\section{Results}

The same approach also was widely adopted by many engineering schools in earlier times to incorporate the environment into engineering curricula. Many have started integrating the environment into traditional engineering subjects, offering more specialised environmental subjects as optional units in engineering curricula and developing environmental engineering undergraduate programmes. Teaching environmental engineering, according to the diversity of needs of students at different levels, focusing on diversity and flexibility of the actual engineering education for the students to create a diversity of innovative teaching system, to guide students through a variety of channels in the face of environmental pollution problems when speculative independent innovation to the student, through innovative teaching activities to increase students' freedom and cooperation in space, to enable students to increase passive aggressive self-innovation capability. Meanwhile, through innovative teaching activities can also increase the integration of students, self-control, independence, generosity, tolerance and dedication to improve students' career in the field of environmental engineering level, to build a harmonious society and the future of social services of circular economy.

\section{References}

[1] Ujang, Z., Henze, M., Curtis, T., Schertenieib, R. and Beal, L.L., Environmental engineering education for developing countries: framework for the future. Water Sci. and Tech., Vol. 49(2004), p.1-10

[2] Jo Dewulf, Herman Van Langenhove. Renewables-based Technology [M] . US: John Wiley \& Sons(2006).

[3] Tansel, B., Changing the status quo in environmental engineering education in response to emerging markets. J. of Prof. Issues in Engng. Educ. and Practice, Vol. 134(2008), p.197-201

[4] WHO/UNICEF/WSSCC, Global Water Supply and Sanitation Assessment 2000 Report. Geneva: World Health Organisation (2000).

[5] Ujang, Z. and Buckley, C., Promoting sustainable industry through Waste Minimisation Club. Water Sci. and Tech., Vol. 46(2002), p.1-10

[6] Roriguez-Roda, I., Castella, F., Flotats, X., Lema, J. and Tejero, I., Environmental engineering education in Spain. Water Sci. and Tech., Vol. 49(2004), p.101-108

[7] Alha, K., Holliger, C., Larsen, B.S., Purcell, P. and Rauch, W., Environmental engineering education - summary report of the 1st European Seminar. Water Sci. and Tech., Vol. 41(2000), p.1-7

[8] Takashi Asano and Audrey D. Levine, Wastewater reclamation, recycling and reuse: past, present, and future [J]. Water Sci. and Tech., Vol. 33(1996), p.1-14

[9] Mino, T., Environmental engineering education in Japan. Water Sci. and Tech., Vol. 41(2000), p.17-22 